Химухин С. Н., Еремина К. П., Ри Хосен, Ри Э. Х., Черномас В. В.

S. N. Khimukhin, K. P. Eremina, Khosen Ri, E. H. Ri, V. V. Chernomas

ПОВЕРХНОСТНОЕ ПЛАСТИЧЕСКОЕ ДЕФОРМИРОВАНИЕ ЭЛЕКТРОИСКРОВЫХ ПОКРЫТИЙ

\title{
SURFACE PLASTIC DEFORMATION OF ELECTRO-SPARK COATINGS
}

Химухин Сергей Николаевич - доктор технических наук, доцент, заведующий лабораторией «Конструкционные и инструментальные материалы» Института материаловедения Хабаровского научного центра Дальневосточного отделения Российской академии наук (Россия, Хабаровск).

E-mail: ximyxin@yandex.ru.

Mr. Sergei N. Khimukhin - Doctor of Engineering, Associate Professor, Constructive and tool material laboratory chief, Institute of Materials, Khabarovsk Scientific Centre, Far East Branch of the Russian Academy of Science (Russia, Khabarovsk). E-mail: ximyxin@yandex.ru.

Еремина Ксения Петровна - инженер кафедры «Литейное производство и технология металлов» Тихоокеанского государственного университета (Россия, Хабаровск). E-mail: bksenya_p@bk.ru.

Ms. Ksenia P. Eremina - Engineer, Foundry production and Metal Technologies Department, Pacific National University (Russia, Khabarovsk). E-mail: ximyxin@yandex.ru.

Ри Хосен - доктор технических наук, профессор кафедры «Литейное производство и технология металлов» Тихоокеанского государственного университета (Россия, Хабаровск).

Mr. Ri Khosen - Doctor of Engineering, Professor, Foundry production and Metal Technologies Department, Pacific National University (Russia, Khabarovsk).

Ри Эрнст Хосенович - доктор технических наук, профессор, заведующий кафедрой «Литейное производство и технология металлов» Тихоокеанского государственного университета (Россия, Хабаровск). E-mail: erikri999@mail.ru.

Mr. Ri Ernst Kh. - Doctor of Engineering, Professor, Head of Foundry production and Metal Technologies Department, Pacific National University (Russia, Khabarovsk). E-mail: erikri999@mail.ru.

Черномас Вадим Владимирович - доктор технических наук, профессор Комсомольского-на-Амуре государственного технического университета (Россия, Комсомольск-на-Амуре).

E-mail: userman10@mail.ru.

Mr. Vadim V. Chernomas - Doctor of Engineering, Professor, Komsomolsk-on-Amur State Technical University (Russia, Komsomolsk-on-Amur). E-mail: userman10@mail.ru.

Аннотация. Приведены результаты исследований влияния поверхностного пластического деформирования (ППД) на параметры поверхности покрытий, сформированных методом электроискрового легирования (ЭИЛ). В качестве установки для ППД использовали комплекс безабразивной ультразвуковой финишной обработки (БУФО). При БУФО бронзы была установлена необходимость нескольких проходов индентора БУФО для существенного снижения параметров шероховатости поверхности. Изучено влияние БУФО на показатели шероховатости интерметаллидных покрытий на стали 20Х13. Показана перспективность использования БУФО для уменьшения количества поперечных трещин в покрытиях, сформированных методом ЭИЛ. Для оценки эффективности обработки поверхности покрытия методом БУФО предложено дополнительно использовать (наряду с $R a$ ) параметры $R k, R p k, R v k$, которые более полно позволяют оценить полученную поверхность как трехкомпонентную. Установлено, что количество проходов при обработке интерметаллидных покрытий не должно быть более шести. Показана необходимость учета величины исходной шероховатости для достижения максимальной эффективности процесса обработки. 
Химухин С. Н., Еремина К. П., Ри Хосен, Ри Э. Х., Черномас В. В.

ПОВЕРХНОСТНОЕ ПЛАСТИЧЕСКОЕ ДЕФОРМИРОВАНИЕ ЭЛЕКТРОИСКРОВЫХ ПОКРЫТИЙ

Summary. The research provides facts about the surface plastic deformation (SPD) effect on the coatings surface parameters formed by electro-spark alloying (ESA). The complex for nonabrasive ultrasonic finishing (NUF) was used as the installation for SPD. It was found out that when processing bronze by NUF several passes of indenter were needed to provide substantial decrease of the surface roughness parameters. The NUF effect on roughness parameters of intermetallic coatings on steel $20 \mathrm{X} 13$ was studied. NUF proved to be perspective when it is necessary to reduce the number of transverse cracks in the coatings formed by ESD method. In order to assess the efficiency of coating surface treatment by NUF method the use of additional parameters Rk, Rpk, Rvk alongside with Ra are recommended as they allow assessing the resulting surface as triple. It is found out that the number of passes during the processing of intermetallic coatings should not exceed 6. For achieving maximum processing efficiency it is necessary to take into consideration the initial roughness value.

Ключевые слова: поверхностно-пластическое деформирование, электроискровое легирование, шероховатость, покрытие.

Key words: surface plastic deformation, electro-spark alloying, roughness, coating.

УДК 621.03; 620.179.16

Повышение эффективности современного машиностроительного комплекса невозможно без получения новых материалов и технологий. Из анализа условий работы большинства деталей следует, что нет необходимости создавать деталь из нового материала целиком, достаточно получить на ее поверхности покрытие. В настоящее время существует большое количество методов, обеспечивающих получения покрытий с заданными свойствами. Каждый из методов имеет свои достоинства и недостатки. Наибольший интерес представляют методы, использующие источники концентрированных потоков энергии (взрывной, плазменный, лазерный). К их числу относится и метод электроискрового легирования, основанный на физическом явлении электроискрового взаимодействия между анодом (обрабатывающим электродом) и катодом (деталью) [1]. Достоинствами метода ЭИЛ является высокая прочность сцепления покрытия и материала основы, возможность нанесения на упрочняемую поверхность любых токопроводящих материалов, в том числе тугоплавких металлов и сплавов, низкая энергоемкость процесса, простота выполнения технологической операции. При этом существует ряд недостатков, которые сдерживают более широкое распространение метода ЭИЛ в промышленном производстве. Наряду с недостаточной изученностью процесса структурообразования в покрытии и отсутствием автоматизированных комплексов по нанесению покрытий необходимо существенно снизить параметры шероховатости поверхности покрытия. Под шероховатостью поверхности понимается как один, так и несколько параметров. Для оценки шероховатости покрытий в данной работе предлагается использовать опыт зарубежных стран (Японии, Германии и др.), где дополнительно к традиционным $R a$ и $R z$ используют параметры $R k, R p k$ и $R v k$ [2]. Условно эти параметры характеризуют окончательно полученную поверхность как трехкомпонентную, состоящую отдельно из выступов (Rpk), основного профиля $(R k)$ и впадин $(R v k)$.

Снижение шероховатости формируемого покрытия необходимо на деталях, работающих при трении-скольжении и в ряде других случаев, например на лопатках газотурбинных агрегатов. В последнем случае создаваемое покрытие должно обладать дополнительно высокой жаростойкостью. Некоторое снижение шероховатости покрытия возможно в рамках самого процесса ЭИЛ. Так, в зависимости от характера движения торцевой поверхности анода используются вибрирующая и вращающаяся головки. При этом максимальная толщина и шероховатость покрытия получается при использовании вибрирующей головки, и наоборот: указанные показатели снижаются при применении вращательной головки. Уменьшить шероховатость можно и подбором энергетического режима электроискровой установки. И все же существенно снизить шероховатость, доведя ее до величины, соответствующей чистовому 
режиму токарной обработки, в рамках собственно процесса ЭИЛ невозможно. Из методов, позволяющих уменьшить шероховатость поверхности, наибольшее распространение получило шлифование, меньшее - поверхностное пластическое деформирование [3]. Для ЭИЛ наиболее целесообразно использовать ППД, т.к. толщина полученных слоев (до 0,5 мм) не позволяет применять шлифование. Процесс формирования покрытий методом ЭИЛ фактически является закалкой расплава из жидкого состояния. Высокая скорость охлаждения, по разным оценкам достигающая $10^{-5} \mathrm{c}$, при кристаллизации подавляет диффузионные и релаксационные процессы в металле, что приводит к формированию напряжений растяжения в покрытии. Напряжения растяжения достигают больших значений и могут приводить к возникновению характерных поперечных трещин и отслаиванию покрытий по границе с основой. При использовании ППД в обрабатываемом поверхностном слое формируются напряжения сжатия [4], поэтому обработка ППД позволяет не только уменьшить шероховатость поверхности покрытия, но и приводит к уменьшению поперечных трещин в слое. В настоящее время метод ППД реализован на устройствах обкатывания, где рабочий наконечник индентор воздействует на поверхность обработки посредством статического давления. Менее распространены устройства, осуществляющие безабразивную ультразвуковую финишную обработку [5]. Принцип действия БУФО отличается тем, что индентор производит ударные воздействия на поверхность покрытия с ультразвуковой частотой, поэтому механизм формирования структуры имеет некоторые особенности. В работе исследуется процесс изменения шероховатости интерметаллидных покрытий, полученных методом ЭИЛ при обработке БУФО.

\section{Методика и материалы}

В качестве анодов для получения покрытий использовали сплавы алюминидов никеля составов A (мас. \%: NI - 67, AL - 33), и Б (мас. \%: NI - 79, AL - 20) [6]. Катодными материалами являлась бронза БрО10 и сталь марки 20Х13. Для получения покрытий использовали установки Элитрон 22 А и Корона 1103. После отработки оптимальных режимов нанесения и изучения структуры покрытий было установлено, что наиболее целесообразно использовать установку Корона 1103, поэтому все приведенные в работе покрытия были получены с использованием этой установки. Уменьшение шероховатости поверхности покрытий производилось при использовании комплекса БУФО, включающего ультразвуковой генератор ИЛ10-2.0. Рабочий орган с индентором закрепляли в резцедержателе токарного станка на 3 мм выше центра вращения образца. Покрытие наносилось на торцевую поверхность образца, предварительно обработанную резцом. В используемом комплекте БУФО индентор изготовлен из твердого сплава, что способствует длительному сохранению его исходных размеров без изменений. Для отработки технологии БУФО покрытий обработку проводили по линиям. Индентор ультразвукового инструмента перемещался по линии поперек торцевой поверхности образца, закрепленного неподвижно в патроне токарного станка. В процессе обработки БУФО образец не вращался, поэтому имелась возможность провести различное количество проходов индентора по одной линии. Выбранная схема эксперимента позволяет имитировать изменение шероховатости поверхности образцов при различном количестве обработок. Количество проходов индентора по одной линии было различным $(1,3,6,12,24$ и в отдельных случаях 50). Микроструктурные исследования проводили с использованием оптического микроскопа «Planar Micro-200», растрового электронного микроскопа SU-70 Hitachi. Параметры шероховатости поверхности образцов исследовали при помощи профилографа Surfcom1800D фирмы Accretech.

\section{Полученные результаты и обсуждение}

На рис. 1 приведена структура поперечных шлифов после нанесения покрытия методом ЭИЛ (рис. 1, a), где видны поперечные трещины, длина которых достигает основы. Из анализа результатов собственных экспериментов и литературных данных можно сделать вывод, что указанные трещины возникают вследствие возникновения в покрытии напряжений 
Химухин С. Н., Еремина К. П., Ри Хосен, Ри Э. Х., Черномас В. В.

растяжения. После обработки покрытия методом БУФО (рис. 1, б) количество поперечных трещин уменьшается, при этом длина оставшихся трещин существенно меньше. Уменьшение количества трещин обусловлено их завариванием и косвенно свидетельствует об отсутствии оксидных плен на внутренней поверхности большинства трешин. Наличие оксидных плен на внутренней поверхности трещин вне зависимости от ширины их раскрытия не позволяет им завариваться, поэтому в работе стремились уменьшить время между технологическими операциями ЭИЛ и БУФО, что в ряде случаев позволит уменьшить число не заваривающихся трещин в покрытии.

При проведении предварительных экспериментов было установлено, что однократный проход индентора БУФО (обработка один раз) является не достаточным, поэтому необходимо установление оптимального количества проходов. Для этого провели модельный эксперимент с использованием образцов БрО10 без покрытия, после токарной обработки $(R a$ от 5 до10 мкм). В качестве критерия эффективности БУФО использовали риски, оставшиеся на поверхности обработки от резца, и структуру измененной поверхности. Из анализа полученных результатов следует, что после однократного прохода индентора на поверхности образцов заметны исходные риски. Увеличение количества проходов индентора до 6 раз существенно снижает количество исходных рисок. После $12-24$ проходов заметно увеличивается число и размер участков, где заметны признаки пластического деформирования материала. На этих участках обнаружены трещины, характерные для перенаклепанного материала со следами разрушения (деструкция). Дальнейшее увеличение количества проходов (до 50) вызывает рост площади участков с деструкцией. Таким образом, полученные результаты показали, что оптимальное количество проходов индентора не должно превышать 6 даже при обработке относительно пластичного материала БрО10.

a)

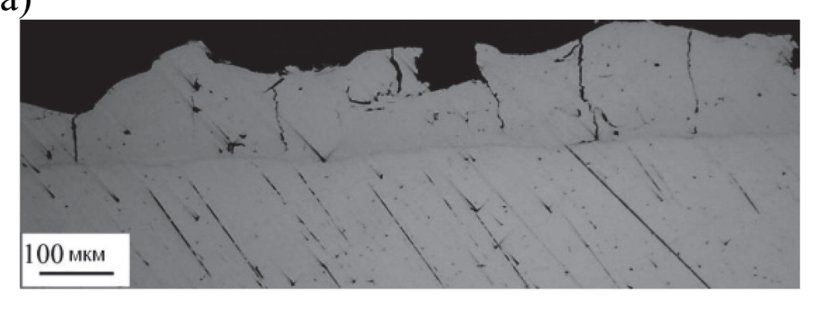

б)

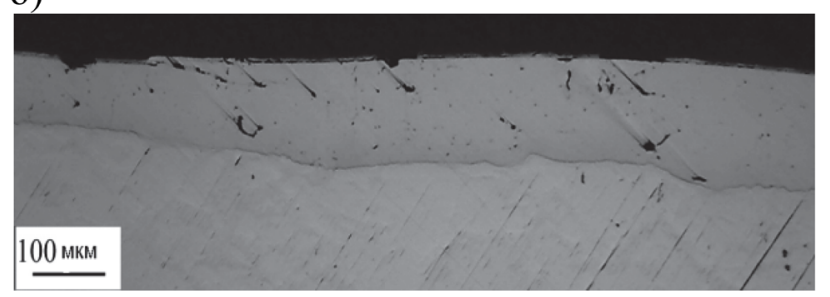

Рис. 1. Микроструктура образцов с покрытиями:

a - после получения покрытия методом ЭИЛ; б - после получения покрытия методом ЭИЛ и последующей обработки методом БУФО

В качестве объектов для изучения влияния обработки БУФО использовали покрытия, сформированные сплавами А и Б на катодах из стали 20Х13. Как и в предыдущем случае, обработку проводили по линии с различным количеством проходов индентора БУФО по одному месту. Для анализа изменения шероховатости использование только параметров $R a, R q$ или $R z$ не целесообразно, т.к. в основном они предназначены для оценки параметров поверхностей, имеющих регулярность. Поверхность покрытий, полученных методом ЭИЛ, не имеет регулярности, что объясняется стохастическим характером процесса искрообразования [7], который определяет структуру поверхности покрытия. Кроме этого, выбор для оценки эффективности использования БУФО при различном количестве проходов параметров $R k, R p k$ и $R v k$ обусловлен тем, что их снижение в большей степени отражает положительное влияние на уменьшение износостойкости, коррозионной стойкости и жаростойкости. Используемый в работе для получения покрытий интерметаллидный сплав $\mathrm{Ni}_{3} \mathrm{Al}$ применяется для жаростойких покрытий. 


\section{Ученые записки

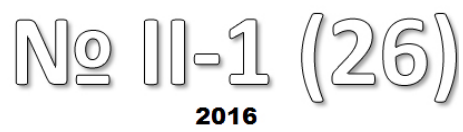

На рис. 2 приведены гистограммы параметров, изменяющихся в зависимости от количества проходов. Гистограммы представлены в два столбика, которые отражают параметры шероховатости покрытий, нанесенных различными сплавами А и Б (слева - А, справа - Б). Значение «0» на оси абсцисс обозначает исходные значения параметров поверхности после ЭИЛ.

a)

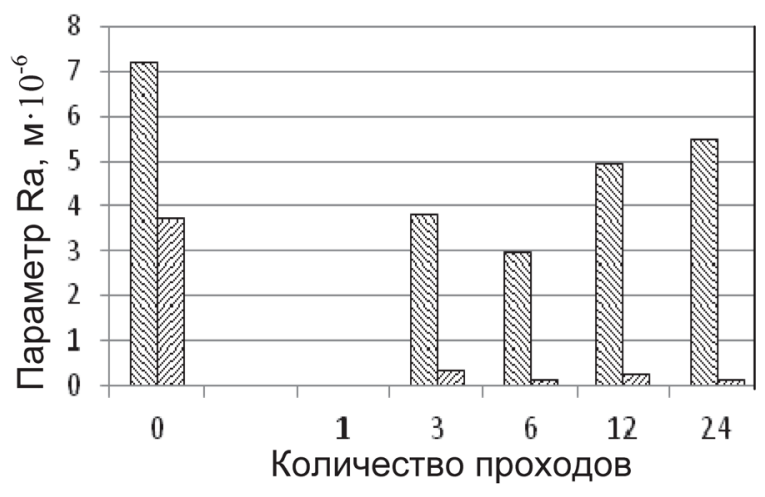

B)

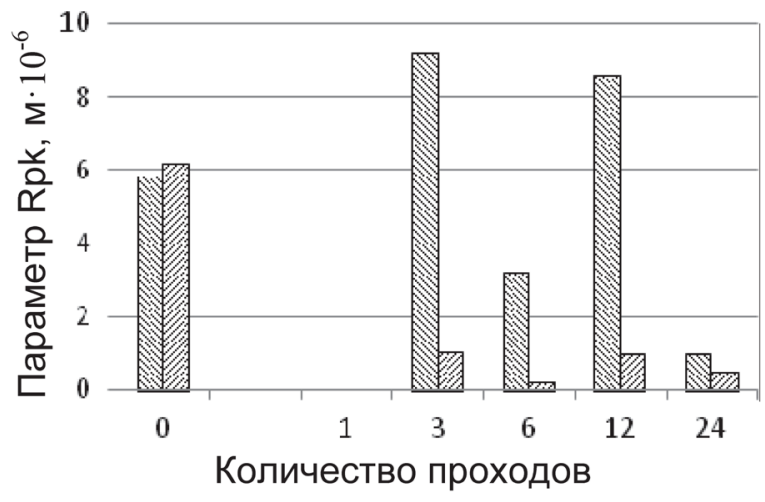

б)

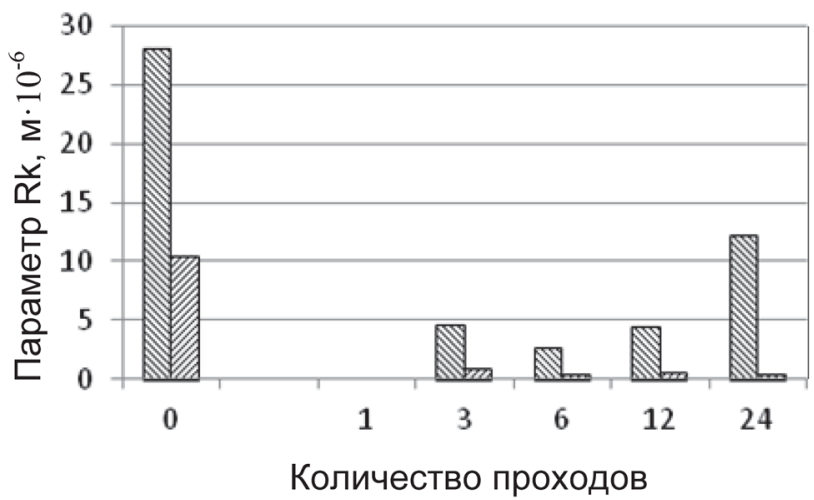

г)

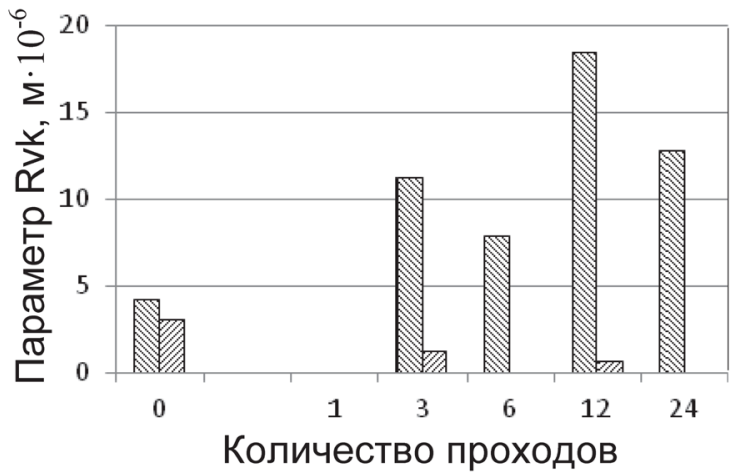

Рис. 2. Параметры шероховатости покрытия, полученного с использованием ЭИЛ и различного количества проходов БУФО:

a - среднее арифметическое отклонение профиля $(R a)$;

б - глубина неровностей профиля поверхности $(R k)$;

в - усредненная высота выступов $(R p k)$;

$\Gamma-$ усредненная глубина впадин профиля $(R v k)$

Как следует из полученных результатов (см. рис. 2), после 3 - 6 проходов индентора параметры $R a, R k$ практически не изменяются или даже несколько возрастают $(R p k, R v k)$, поэтому наиболее целесообразно для обработки покрытий использовать 3 - 6 проходов. Интересно, что оптимальное количество проходов индентора при обработке покрытий и сплава БрО10 после токарной обработки существенно не отличается, хотя покрытия сплавами $\mathrm{Ni}_{3} \mathrm{Al}$ существенно менее пластичны.

Необходимо отметить существенно большие величины параметров шероховатости при использовании сплава А как после ЭИЛ, так и после различного количества проходов индентора БУФО. Более высокие параметры шероховатости после ЭИЛ объясняются результатами фрактографических исследований, где установлено, что структура сплава А состоит из более крупных структурных составляющих [8]. Последующей обработкой БУФО снизить исходные высокие параметры шероховатости не удается, поэтому существенное значение 
Химухин С. Н., Еремина К. П., Ри Хосен, Ри Э. Х., Черномас В. В.

для БУФО имеют исходные параметры шероховатости поверхности. При анализе структуры поверхности покрытий после обработки было замечено наличие некоторого количества срезов микровыступов. По-видимому, эти структурные составляющие возникают в случае, когда исходные параметры шероховатости поверхности больше, чем амплитуда колебания индентора. При таком режиме работы установки БУФО амплитуда колебания индентора уменьшается, что приводит к снижению эффекта пластического деформирования из-за выхода системы прибора из режима резонанса, поэтому для эффективной работы БУФО необходимо учитывать исходные параметры шероховатости поверхности и предусмотреть их уменьшение при изначально высоких значениях.

На основании проведенных исследований можно сформулировать ряд выводов:

1) Финишная обработка интерметаллидных электроискровых покрытий методом БУФО обеспечивает существенное уменьшение числа поперечных трещин в покрытии и снижение параметров шероховатости поверхности.

2) Оптимальное количество проходов индентора БУФО при обработке покрытия, сформированного интерметаллидными сплавами, составляет 3 - 6 раз.

3) Для наиболее эффективной работы БУФО необходимо учитывать исходную шероховатость покрытий.

\section{ЛИТЕРАТУРА}

1. Формирование структуры слоя на металлах и сплавах при электроискровой обработке / С. Н. Химухин [и др.]. - Хабаровск: Изд-во ДВГУПС, 2010. - 240 с.

2. Табенкин, А. Н. Шероховатость, волнистость, профиль. Международный опыт / А. Н. Табенкин, С. Б. Тарасов, С. Н. Степанов; под ред. Н. А. Табачниковой. - СПб.: Изд-во Политехн. ун-та, 2007. $136 \mathrm{c}$.

3. Смелянский, В. М. Механика упрочнения деталей поверхностным пластическим деформированием / В. М. Смелянский. - М.: Машиностроение, 2002. - 300 с.

4. Особенности формирования субструктуры поверхностного слоя некоторых металлов после электроискрового легирования и поверхностной пластической деформации / А. И. Михайлюк [и др.] // Электронная обработка материалов. - 1995. - № 1.

5. Холопов, Ю. В. Машиностроение: ультразвук: УЗС, БУФО, ГЕО / Ю. В. Холопов. - СПб.: Типография «Береста», 2008. $-328 \mathrm{c.}$

6. Электродный материал из алюминидов никеля / С. Н. Химухин [и др.] // Вопросы материаловедения. - 2012. - № 3(71). - С. 97-102.

7. Химухин, С. Н. Условия возникновения искрового процесса при низковольтной электроискровой обработке / С. Н. Химухин // Упрочняющие технологии и покрытия. - 2007. - № 1. - С. 12-15.

8. Получение сплавов на основе алюминидов никеля / С. Н. Химухин [и др.] //Фундаментальные и прикладные проблемы техники и технологии. - 2012. - № 2-6. - С. 75-81. 